Research Article

\title{
Proactive Hedging European Call Option Pricing with Linear Position Strategy
}

\author{
Meng Li $(\mathbb{D}$, Xuefeng Wang, and Fangfang Sun \\ School of Management, Harbin Institute of Technology, Harbin 150001, China \\ Correspondence should be addressed to Fangfang Sun; fangfang@hit.edu.cn
}

Received 2 July 2018; Accepted 15 August 2018; Published 17 September 2018

Academic Editor: Allan C. Peterson

Copyright (C) 2018 Meng Li et al. This is an open access article distributed under the Creative Commons Attribution License, which permits unrestricted use, distribution, and reproduction in any medium, provided the original work is properly cited.

\begin{abstract}
Proactive hedging option is an exotic European stock option designed for hedgers. Such option requires option holders to buy in (or sell out) the underlying asset (stock) and allows them to adjust the holdings of the underlying asset per its price changes within an option period. The proactive hedging option is an attractive choice for hedgers because its price is lower than that of classical options and because it completely hedges the risk of exposure for option holders. In this study, the underlying asset price movement is assumed to follow geometric fractional Brownian motion. The pricing formula for proactive hedging call options is derived with a linear position strategy by applying the risk-neutral evaluation principle. We use simulations to confirm that the price of this exotic option is always no more than that of the classical European option under the same parameters.
\end{abstract}

\section{Introduction}

The classical option was first introduced in the 1970s by the Chicago Board Options Exchange (CBOE). Various option instruments have since followed to cater to the diverse array of transaction purposes among investors including speculation, arbitrage, or hedging. Scholars and traders alike [1-6] have investigated the pricing and price dynamics of exotic options in effort to help investors trade them on the market.

The "option", by design, is a hedging tool for investors who hold or intend to hold an underlying asset. When the price of an underlying asset intersects the option exercising price, the option goes into effect and the option holder may trade in or sell out the underlying asset at exercising price from the option writer. However, if the price of the underlying asset does not intersect the exercising price, the option holder loses the money he or she initially paid for the option. The option holder inherently prefers any lower option price as it represents a lower hedging cost. The option enables the option holder to trade the asset at an advantageous price, however, so that a risk-free arbitrage is available between the exercising price and market price. The return from such risk-free arbitrage and the option price leverage each other; this phenomenon has attracted a great deal of speculators to the market. Many exotic options, including binary options, lookback options, and "as-you-like-it" options center around the interests of speculators rather than hedgers, although hedging is, in actuality, the most elementary function of options.

The present study was conducted to explore an exotic option called the "proactive hedging option", which serves to lower the hedging cost passed on to the option holder. The proactive hedging option combines the classical European option with a mandatory constraint, which requires the option holder to adjust the amount of the on-hold underlying asset according to the contracted strategy. This constraint is expected to lower the option fee, as the option holder themselves cover part of the risk on the sell side by exercising the contracted strategy. This paper explicitly details the design of the proactive hedging option under a linear position strategy and derives the pricing of the exotic option accordingly.

1.1. Proactive Hedging Option. Option traders typically include speculators and hedgers with various goals and strategies as they navigate the market. Speculators seek to gain excessive returns by virtue of option leverage, so their primary concern is leverage effects; the expected return tends to be higher for a larger leverage. Unlike speculators, hedgers seek to cover their risk of exposure at a minimum cost, 
namely, the lowest possible option price. In an arbitrage-free financial market, option price depends only on the risk that is transferred to the option writer (the seller). To minimize the option fee, hedgers (buyers) must proactively minimize their exposure to the risk taken by the option writer. The classical option requires that the option writers cover all the expected loss per the difference between the current and the exercising price of the underlying asset as the option holders begin to exercise the option. The option holder has no incentive to hedge the risk at all; this leads to a relatively high option fee.

Asian options are one of the few real choices for hedgers among various exotic options; their price depends on the average price of the underlying asset over the entire life of the option or a certain period within it. Asian options are usually cheaper than classical options, as their contracts are based on the average price of the underlying asset which is relatively stable (and thus such options are less risky). The risk of deviations from average price is covered, so the options are more attractive to hedgers who desire a smooth, continuous, and predictable cash flow over a period of time rather than general hedgers.

For a call/put option holder to cover the risk exposure proactively, they may buy in/sell out their underlying asset according to changes in its price. The option holder, per the position of the underlying asset, may use a return from holding the underlying asset to hedge part of his or her risk. Wang et al. [7-9] proposed an exotic European stock option according to this phenomenon which is referred to here as the "proactive hedging option".

Proactive hedging option holders, per their namesake, seek to proactively cover their risk of exposure; the option writers only bear a residual portion of the risk. This strategy is realized by embedding a mandatory condition into the classical European option, a condition that requires option holders to hold the underlying asset and adjust the holding position linearly according to its price fluctuations. For a call option specifically, the option holders hold a certain amount of capital at the beginning of the option period and they begin to buy into the underlying asset when its price exceeds a certain threshold (usually the exercising price). They increase the holdings based on a linear position strategy if the price continues to rise. The position strategy is predetermined and attached to the option contact as a constraint. In this process, the average buy-in price along the linear position strategy is called the "purchasing price". When the option may be exercised, the option writer takes only the expected loss caused by the difference between the purchasing price and exercising price. A portion of the expected loss created by the difference between the current and purchasing price is offset by the self-defensive asset holding of the option holder and, therefore, not taken by the option writer.

Similarly, for a put option, the option holder retains a certain number of shares of the underlying asset at the beginning of the option period. When the asset price falls below a threshold, they begin to sell out the asset and decrease holdings if the price is on a continual decline based on a given position strategy. In this process, the average sell-out price along the linear position strategy is called the selling price. When the put option may be exercised, the option writer takes the expected loss from the difference between the excising price and selling price. This expected loss is offset by the self-defensive asset selling of the option holders and, therefore, not taken by the option writer. Of course, the proactive hedging option has lower pricing than the classical option as the option writer takes less risk, and it partly hedges the risk of the option holder.

Although the proactive hedging option has a price advantage, it requires a sacrifice of leverage size to some extent because the option holders bear a certain amount of the capital or underlying asset for the purposes of hedging. The leverage of the option grows weaker as the underlying asset option holder gains more capital. When the initial capital exceeds the exercising price multiplied by the number of underlying assets in the option contact, the leverage of the call option disappears completely. Similarly, when the initial holding of the underlying asset exceeds the number of underlying assets in the option contact, the leverage of the put option disappears completely. In short, the proactive hedging option is well-suited to the interests of hedgers.

1.2. Overview of Option Pricing. Financial derivatives' value estimation and pricing are fundamental aspects of effective financial transactions. The asset price should be the best estimate of its true value in an efficient market. The value of an option typically consists of two parts: the intrinsic value generated from the difference between the underlying asset price and the exercising price, and the time value originated from the uncertainty of the underlying asset price. The time value gradually decreases to zero at the maturity date, so the price of an option at the maturity date depends only on its intrinsic value. However, for a given time point before the maturity date, an option must be priced appropriately per its time value.

The Black-Scholes (B-S) model provides a very useful solution in determining the time value of an option. It constructs a risk-neutral portfolio $\Pi$ composed of the option and the opposite transaction of a certain amount of underlying asset $\mathrm{S}$ assuming that the expected return of the underlying asset is a risk-free rate [10]. The risk-neutral world assumes that investors do not need risk compensation and that the expected return of any financial asset has a risk-free rate. Empirical research has shown that the theoretical price as determined by B-S model is reasonably close to the real price of options [11, 12], which has made the B-S model one of the most popular option pricing instruments.

For the classical European option, the B-S model assumes the underlying asset price follows a geometric Brownian motion (GBM). The theoretical price is obtained by applying the Itô Lemma to establish the B-S partial differential equation for the riskless portfolio $\Pi$. The analytic solution must satisfy both the partial differential equation and a boundary condition on the price at the maturity date. The transformation of heat conduction equation can then be applied to obtain the pricing formula [10]. Although the pricing formula derived by this technique provides mathematically 
elegant and powerful option pricing results, the assumption of the underlying asset price following GBM does not usually hold in reality. In fact, there exists long-range positive autocorrelation in stock returns, which is considered to be simply an intrinsic feature of financial markets [13-16]; this conclusion is incompatible with the GBM assumption of the classical B-S model. Geometric fractional Brownian motion (GFBM) is better suited to the properties of financial asset prices [17-21], e.g., fat-tail distribution or volatility clustering. Recent researchers have indeed attempted to deduce B-S models based on GFBM [22-25].

Another approach to obtaining analytic B-S model solutions is to directly apply the risk-neutral evaluation principle as defined by Cox and Ross [26]. The risk-neutral evaluation principle indicates that the expected returns of any financial asset must be a risk-free rate. That is to say, if the price of an option at the maturity date $V(T)$ is given, then the price for any time before that point is a discount value of the expected value of $V(T)$ at the risk-free interest rate. Pricing formulas for any option can be derived directly by applying the risk-neutral evaluation principle provided that the probability density function of the underlying asset price and intrinsic value function distributions are known. This route is simpler and more accessible than the classical route. As discussed below in Section 4, the same pricing formula can be obtained by either method under the same settings.

This paper presents a pricing formula for proactive hedging options based on GFBM and the risk-neutral evaluation principle. We make two main contributions to the current option design and pricing literature and practice. First, we demonstrate that the pricing of a European option can indeed be obtained under both the risk-neutral evaluation principle and B-S model. Secondly, we derive the pricing formula for a proactive hedging option with a linear position strategy and confirm by simulation that the price of the exotic option never exceeds that of the classical European option if they share the same parameter settings.

The rest of this paper is organized as follows. Section 2 discusses a general form of pricing formula for the classical European option based on GFBM by applying the risk-neural evaluation principle. Based on this general form, we develop the pricing for proactive hedging call options and discuss some special forms of the pricing formula in Section 3. Section 4 reports the simulations we ran to compare the theoretical price of a proactive hedging option with that of a classical option under different parameter settings. Section 5 provides a brief summary and conclusion.

\section{Classical European Option Pricing Based on GFBM}

2.1. Asset Price Behavior Based on GFBM. If a Gaussian process $\mathrm{B}_{H}(t), t \geq 0$ follows Fractional Brownian motion (FBM), then it has mean $\mathrm{E}\left[\mathrm{B}_{H}(t)\right]=\mu$ and covariance

$$
\mathrm{E}\left[\mathrm{B}_{H}(\mathrm{t}) \mathrm{B}_{H}(\mathrm{~s})\right]=\frac{1}{2}\left(|t|^{2 H}+|s|^{2 H}-|t-s|^{2 H}\right)
$$

for all $s, t \in \mathrm{R}_{+}$. The Hurst parameter, $H$, is a value from 0 to 1 . Let $t=s$. The variance of FBM can be obtained as follows.

$$
\mathrm{E}\left[\mathrm{B}_{H}(\mathrm{t})\right]^{2}=\frac{1}{2}\left(|t|^{2 H}+|t|^{2 H}-|t-t|^{2 H}\right)=t^{2 H}
$$

The Hurst parameter $H$ is a measure of long-range dependence in the stochastic process of FBM. If $H=1 / 2$, $\mathrm{B}_{H}(t)$ reduces to an uncorrelated Brownian motion series $\mathrm{B}(t)$. A time series with $H$ larger than 0.5 has long-range positive dependence. A larger $\mathrm{H}$ value indicates stronger positive dependence. A time series with $H$ below 0.5 has long-range negative dependence; a smaller $H$ value indicates stronger negative dependence. As mentioned in Section 1, many previous researchers have shown that the price changes of financial assets have long-range positive dependence, so we only consider the case of $H \geq 0.5$ here.

Let $S(t)$ be the asset price at time $t$. If $S(t)$ follows FBM, then it satisfies the following:

$$
\frac{d S(t)}{S(t)}=\mu d t+\sigma d B_{H}(t)
$$

where $S(0)$, the draft $\mu$, and the volatility $\sigma$ of the asset price are all positive constants for $t \geq 0$. We assume $\log (\mathrm{S}(\mathrm{t}))$ follows FBM; that is, that stochastic process $S(t)$ follows GFBM. By applying the fractional Wick-Itô formula, $\mathrm{Hu}$ and Øksendal proved that (3) can be rewritten as follows [27]:

$$
S(t)=S(0) \exp \left(\sigma B_{H}(t)+\mu t-\frac{1}{2} \sigma^{2} t^{2 H}\right) \text {. }
$$

For any two time points $t_{1}$ and $t_{2}$ with $0 \leq t_{1} \leq t_{2} \leq T$, the relationship between $S\left(t_{1}\right)$ and $S\left(t_{2}\right)$ can be obtained by applying (4):

$$
\begin{aligned}
& S\left(t_{2}\right)=S\left(t_{1}\right) \exp \left[\mu\left(t_{2}-t_{1}\right)-\frac{1}{2} \sigma^{2}\left(t_{2}^{2 H}-t_{1}^{2 H}\right)\right. \\
& \left.+\sigma\left(B_{H}\left(t_{2}\right)-B_{H}\left(t_{1}\right)\right)\right] .
\end{aligned}
$$

Equation (5) will later prove very important for deriving the pricing formula.

2.2. Fractional European Option Pricing Formula. This section discusses the pricing formula for the classical European option based on an assumption of GFBM process on asset prices. The risk-neutral evaluation principle is applied to enable this approach.

At the maturity date $T$, the value of the classical European option, $V_{T}$, is equal to its intrinsic value, which can be written as follows:

$$
V_{T}\left(S_{T}\right)= \begin{cases}\left(S_{T}-X_{e}\right)^{+}, & \text {call option } \\ \left(X_{e}-S_{T}\right)^{-}, & \text {put option }\end{cases}
$$

where $X_{e}$, the exercising price, is a given constant and $S_{T}$, the asset price at maturity date $T$, is a random variable. The 
option pricing problem at any time point t, $0 \leq t \leq T$, yields a solution equivalent to the solution of the following:

$$
V_{t}=V(S(t), t)
$$

And it is also identical to the solution of (6) when $t=T$.

According to the risk-neutral evaluation principle discussed in Section 1, the option pricing $V_{t}$ before the maturity date should equal the discounted value of the option value $V_{T}$ at the maturity date; the discount rate should be the risk-free interest rate $r$. The pricing formula can then be obtained by solving

$$
V_{t}=e^{-r(T-t)} \widehat{E}\left[V_{T}\left(S_{T}\right)\right]
$$

where $S_{T}$ is a function of $S(t)$ and $t$. To achieve an analytical solution from (8), we used a result provided by Necula to establish Theorem 1 [28].

Theorem 1. Let $f$ be a function such that $E\left[f\left(B_{H}(T)\right)\right]<\infty$. Then for every $0 \leq t \leq T$,

$$
\begin{aligned}
\widehat{E}_{t} & {\left[f\left(B_{H}(T)\right)\right] } \\
= & \int_{-\infty}^{+\infty} \frac{1}{\sqrt{2 \pi\left(T^{2 H}-t^{2 H}\right)}} \exp \left(-\frac{\left(x-B_{H}(t)^{2}\right)}{2\left(T^{2 H}-t^{2 H}\right)}\right) \\
& \cdot f(x) d x .
\end{aligned}
$$

Theorem 1 allows us to further establish Lemma 2, which gives the value function of a European option at any time point before the maturity date.

Lemma 2. Assume the price of the underlying asset at time point $t, S(t)$, satisfies (3). Then the valuation of the option at time point $t$ is

$$
\begin{aligned}
& V(S(t), t)=\frac{e^{-(T-t) r}}{\sqrt{2 \pi}} \\
& \cdot \int_{-\infty}^{+\infty} V_{T}\left(S(t) e^{\sigma \sqrt{T^{2 H}-t^{2 H}} Z+(T-t) r-\left(\sigma^{2} / 2\right)\left(T^{2 H}-t^{2 H}\right)}\right) \\
& \cdot e^{-Z^{2} / 2} d Z .
\end{aligned}
$$

Here $V_{T}(\cdot)$ is the value function of the European option at maturity $T$.

Proof. Given that the asset price $S(t)$ follows GFBM and satisfies (5), in a risk-neutral world, (5) can be rewritten as

$$
\begin{aligned}
& S\left(t_{2}\right)=S\left(t_{1}\right) \exp \left(r\left(t_{2}-t_{1}\right)-\frac{1}{2} \sigma^{2}\left(t_{2}{ }^{2 H}-t_{1}{ }^{2 H}\right)\right. \\
& \left.\quad+\sigma\left(B_{H}\left(t_{2}\right)-B_{H}\left(t_{1}\right)\right)\right),
\end{aligned}
$$

where $r$ is the risk-free rate. According to (11), we have

$$
\begin{aligned}
S_{T} & =S(t) \exp \left(r(T-t)-\frac{1}{2} \sigma^{2}\left(T^{2 H}-t^{2 H}\right)\right. \\
& \left.+\sigma\left(B_{H}(T)-B_{H}(t)\right)\right) .
\end{aligned}
$$

Combining (12) with (8), we have

$$
\begin{aligned}
& V(S(t), t)=e^{-r(T-t)} \widehat{E}\left[V_{T}\left(S_{T}\right)\right]=e^{-r(T-t)} \widehat{E}\left[V_{T}(S(t)\right. \\
& \quad \cdot \exp \left(r(T-t)-\frac{1}{2} \sigma^{2}\left(T^{2 H}-t^{2 H}\right)\right. \\
& \left.\left.\quad+\sigma\left(B_{H}(T)-B_{H}(t)\right)\right)\right] .
\end{aligned}
$$

Under Theorem 1,

$$
\begin{aligned}
& V(S(t), t)=e^{-r(T-t)} \widehat{E}\left[V_{T}\left(S_{T}\right)\right]=e^{-r(T-t)} \int_{R} V_{T}(S(t) \\
& \cdot \exp \left(r(T-t)-\frac{1}{2} \sigma^{2}\left(T^{2 H}-t^{2 H}\right)\right. \\
& \left.+\sigma\left(x-B_{H}(t)\right)\right) \\
& \cdot \frac{1}{\sqrt{2 \pi\left(T^{2 H}-t^{2 H}\right)}} \exp \left[-\frac{\left(x-B_{H}(t)\right)^{2}}{2\left(T^{2 H}-t^{2 H}\right)}\right] d x .
\end{aligned}
$$

Let $Z=\left(x-B_{H}(t)\right) / \sqrt{T^{2 H}-t^{2 H}}$, so we can obtain (10). Lemma 2 holds. Equation (10) suggests that $S(t) e^{\sigma \sqrt{T^{2 H}-t^{2 H}} Z+(T-t) r-\left(\sigma^{2} / 2\right)\left(T^{2 H}-t^{2 H}\right)}$ is a transformation of $S_{T}(S(t), t)$ under the standard Brownian motion $Z$ measure. In the following example, we deduct the pricing formula of the classical European option with Lemma 2 and show that this pricing formula is identical to the one obtained through B-S equations.

Example 3. Assume a classical European option, the underlying stock price of which follows the GFBM process. The pricing formula of this option can be obtained by plugging the value function equation (6) into (10). We start here with a call option with value function of $\mathrm{V}_{F c}(S(t), t)$ at time point $t$ before the maturity date. Let $U=$ $S(t) e^{\sigma \sqrt{T^{2 H}-t^{2 H}} Z+(T-t) r-\left(\sigma^{2} / 2\right)\left(T^{2 H}-t^{2 H}\right)}$. When $U \geq X_{e}$ (where $X_{e}$ is similar to the exercising price in the B-S model), we have

$$
\begin{aligned}
& \frac{\ln \left(X_{e} / S\right)-(T-t) r+\sigma^{2}\left(T^{2 H}-t^{2 H}\right) / 2}{\sigma \sqrt{T^{2 H}-t^{2 H}}} \leq Z \\
& <+\infty .
\end{aligned}
$$


Consequently,

$$
\begin{aligned}
& V_{F c}(S(t), t)=\frac{e^{-(T-t) r}}{\sqrt{2 \pi}} \\
& \cdot \int_{d_{1}}^{+\infty}\left(S(t) e^{\sigma \sqrt{T^{2 H-} t^{2 H}} Z+(T-t) r-\left(\sigma^{2} / 2\right)\left(T^{2 H-} t^{2 H}\right)}-X_{e}\right) \\
& \cdot e^{-Z^{2} / 2} d Z=\frac{S(t)}{\sqrt{2 \pi}} \int_{d_{1}}^{+\infty} e^{-(1 / 2)\left(Z-\sigma \sqrt{T^{2 H}-t^{2 H}}\right)^{2}} d Z \\
& -\frac{X_{e} e^{-(T-t) r}}{\sqrt{2 \pi}} \int_{d_{1}}^{+\infty} e^{-\left(Z^{2} / 2\right)} d Z=\frac{S(t)}{\sqrt{2 \pi}} \\
& \cdot \int_{d_{1}-\sigma \sqrt{T^{2 H}-t^{2 H}}}^{+\infty} e^{-(1 / 2)\left(Z-\sigma \sqrt{T^{2 H}-t^{2 H}}\right)^{2}} d(Z \\
& \left.-\sigma \sqrt{T^{2 H}-t^{2 H}}\right)-\frac{X_{e} e^{-(T-t) r}}{\sqrt{2 \pi}} \int_{d_{1}}^{+\infty} e^{-Z^{2} / 2} d Z \\
& =S(t)\left(N\left(-d_{2}\right)\right)-X_{e} e^{-(T-t) r}\left(N\left(-d_{1}\right)\right)
\end{aligned}
$$

where

$$
\begin{aligned}
& d_{1}=\frac{\ln \left(X_{e} / S\right)-(T-t) r+\left(\sigma^{2} / 2\right)\left(T^{2 H}-t^{2 H}\right)}{\sigma \sqrt{T^{2 H}-t^{2 H}}}, \\
& d_{2}=\frac{\ln \left(X_{e} / S\right)-(T-t) r-\left(\sigma^{2} / 2\right)\left(T^{2 H}-t^{2 H}\right)}{\sigma \sqrt{T^{2 H}-t^{2 H}}},
\end{aligned}
$$

and $\mathbf{N}(\cdot)$ indicates the cumulative probability of the standard normal distribution. By applying the same approach, we can get the pricing formula for the put option:

$$
V_{F p}(S(t), t)=X_{e} e^{-(T-t) r}\left(N\left(d_{1}\right)\right)-S(t)\left(N\left(d_{2}\right)\right) .
$$

Formulas (16) and (18) are identical to the pricing formulas used by $\mathrm{Hu}$ and $\varnothing \mathrm{ksendal}$ [27], which were obtained by solving B-S partial differential equations.

\section{Proactive Hedging European Call Option Pricing Model with Linear Position Constraint}

3.1. Pricing Model Assumptions. Here, we add or modify the following assumptions based on the B-S pricing model:

(i) The option has underlying stock prices following FBM with the draft $\gamma$ and volatility $\sigma$.

(ii) A call option holder should hold an initial capital of amount $A=Q \times X_{e}$ at the beginning of the option period for each piece of an option contract, where $Q$ is the stock unit of one option contract piece.

(iii) Option holders adjust the underlying stock holdings according to the price changes subject to the linear position constraint attached to the option contract.

3.2. Linear Position Strategy. The continuous linear position constraint was first proposed by Wang et al. [8]. It assumes that an option holder holds an initial capital of amount $A$ for the piece of the option. When the price of the underlying stock reaches $X_{e}+\delta(\delta \geq 0)$, the option holder spends $\beta_{0} \cdot A$ (for) on buying the stock at a given time, where $\beta_{0}, 0 \leq \beta_{0} \leq 1$, which denotes the proportion of capital spent, is the "capital utilization coefficient".

The option holder linearly and continuously adjusts the capital utilization to increase the holdings if the price continues to rise until reaching $(1+\alpha)\left(X_{e}+\delta\right)$, where $\alpha$ is a positive number referred to as the "investment strategy index". The highest utilization coefficient of the capital is $\beta$, so $0 \leq \beta_{0} \leq \beta \leq 1$; that is, the option holder can spend at most $\beta \cdot A$ in total on holding the stock when the price reaches $(1+\alpha)\left(X_{e}+\delta\right)$ and no longer will increase the holding when the price exceeds this threshold. The capital utilization coefficient function along this process, $B(S)$, can be expressed as follows.

$$
B(S)= \begin{cases}0 & S(t)<X_{e}+\delta \\ \frac{\beta-\beta_{0}}{\alpha\left(X_{e}+\delta\right)}\left(S(t)-X_{e}-\delta\right)+\beta_{0} & X_{e}+\delta \leq S(t)<(1+\alpha)\left(X_{e}+\delta\right) \\ \beta & S(t) \geq(1+\alpha)\left(X_{e}+\delta\right)\end{cases}
$$

Equation (19) is also graphically illustrated in Figure 1.

\subsection{Proactive Hedging Option Value Function with Linear} Position Strategy. As noted in Section 1, the value of an option essentially depends on how much risk is transferred to the option writer. If an exotic option allows the option holder to take self-defense strategies, then its value is determined by the difference of the expected loss taken by the option writer in the classical European option and the returns from the self-defense strategies taken by the option holder. The classical European option holder does not carry out any self-defense strategy, so she will suffer an expected loss (20) for each piece of the option contract as the stock price rises from $X_{e}$ to $S_{0}$.

$$
L_{b}\left(S_{0}\right)=\frac{A}{X_{e}}\left(S_{0}-X_{e}\right)
$$

Meanwhile, in an exotic option allowing holder's selfdefense strategy, like the proactive hedging option with linear 


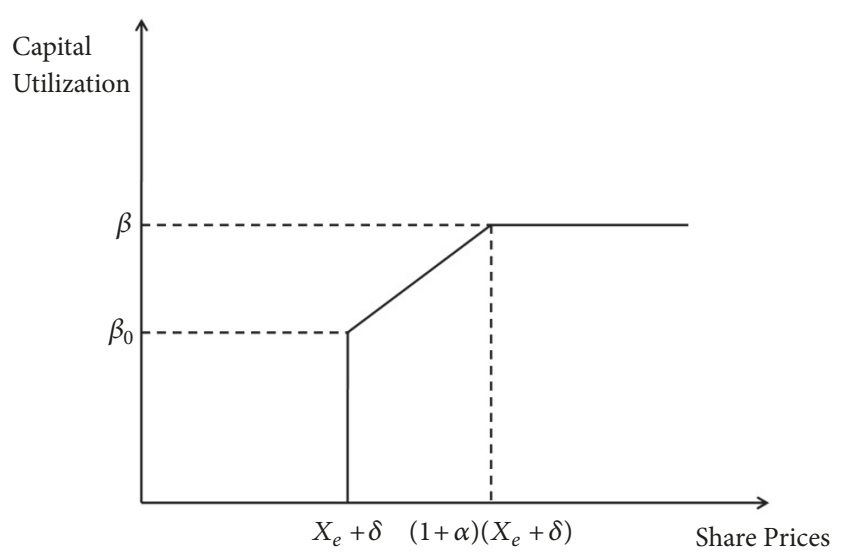

FIGURE 1: Capital utilization coefficient function along stock price under linear position strategy. position strategy, the option holder will spend additional amount of capital, $\Delta q$, on buying the stock when the price changes from $S$ to $S+\Delta S$, such that

$$
\Delta q=\Delta Q \cdot A \approx Q^{\prime}(S) \cdot \Delta S \cdot A
$$

where $\Delta Q$ is the rate of the increased capital for buying the stock. Thus, when the stock price reaches $S_{0}$, this stock holding will have an extra return $\Delta R$ :

$$
\Delta R=\frac{\Delta q}{S}\left(S_{0}-S\right)=\frac{A Q^{\prime}(S) \Delta S}{S}\left(S_{0}-S\right)
$$

where $\Delta q / S$ indicates the additional stock units purchased by using the additional capital $\Delta q$. When the stock price rises from $X_{e}+\delta$ (when the self-defense strategy is triggered) to $S_{0}$, the excepted return to the option holder is as follows.

$$
R\left(S_{0}\right)= \begin{cases}\int_{X_{e}+\delta}^{S_{0}} \frac{A \cdot Q^{\prime}(S)}{S} \cdot\left(S_{0}-S\right) d S+\frac{A \cdot \beta_{0}}{X_{e}+\delta} \cdot\left(S_{0}-X_{e}-\delta\right), & \left(X_{e}+\delta\right) \leq S_{0} \leq(1+\alpha)\left(X_{e}+\delta\right) \\ \int_{X_{e}+\delta}^{(1+\alpha)\left(X_{e}+\delta\right)} \frac{A \cdot Q^{\prime}(S)}{S} \cdot\left(S_{0}-S\right) d S+\frac{A \cdot \beta_{0}}{X_{e}+\delta} \cdot\left(S_{0}-X_{e}-\delta\right), & (1+\alpha)\left(X_{e}+\delta\right) \leq S_{0}\end{cases}
$$

Then the expected loss taken by the option writer is as follows.

$$
L\left(S_{0}\right)=L_{b}\left(S_{0}\right)-R\left(S_{0}\right)
$$

Folding (19), (20), and (23) into (24) yields the value function of the exotic option, the self-defense strategy:

$$
\begin{gathered}
V_{T}(\cdot) \\
=\left\{\begin{array}{cc}
V_{T 1}(\cdot), & S<X_{e} \\
V_{T 2}(\cdot), & X_{e} \leq S \leq X_{e}+\delta \\
V_{T 3}(\cdot), & X_{e}+\delta \leq \delta \leq(1+\alpha)\left(X_{e}+\delta\right) \\
V_{T 4}(\cdot), & (1+\alpha)\left(X_{e}+\delta\right) \leq S
\end{array}\right.
\end{gathered}
$$

$$
\begin{aligned}
V_{T 4}(\cdot)= & \left(S-X_{e}\right)\left(1-\frac{\beta_{0} X_{e}}{X_{e}+\delta}\right) \\
& -\frac{\left(\beta-\beta_{0}\right) S X_{e}}{\alpha\left(X_{e}+\delta\right)} \ln (1+\alpha) \\
& +X_{e}\left(\left(\beta-\beta_{0}\right)+\frac{\beta_{0} \delta}{X_{e}+\delta}\right) .
\end{aligned}
$$

3.4. Proactive Hedging Option Pricing Formula Based on GFBM. This section discusses the pricing formula for exotic options under the assumptions that (1) they allow option holders to take the linear position proactive hedging strategy as described in Section 3.2 and (2) the prices of underlying stocks follow GFBM process. With a similar approach to Example 3, the pricing formula is obtained by solving the integral expression after combining the value function in (25) and the pricing formula of the fractional European option in (10). The value function in (25) is a stepwise function, so the pricing formula consists of four parts:

$$
\begin{aligned}
V_{F E c}(S(t), t)= & V_{1}(S(t), t)+V_{2}(S(t), t) \\
& +V_{3}(S(t), \mathrm{t})+V_{4}(S(t), t),
\end{aligned}
$$

where

$$
\begin{aligned}
& V_{1}(S(t), t)=\frac{e^{-r(T-t)}}{\sqrt{2 \pi}} \int_{S<X_{e}} V_{T 1}(\cdot) e^{-Z^{2} / 2} d Z \\
& V_{2}(S(t), t)=\frac{e^{-r(T-t)}}{\sqrt{2 \pi}} \int_{X_{e} \leq S \leq X_{e}+\delta} V_{T 2}(\cdot) e^{-Z^{2} / 2} d Z \\
& V_{3}(S(t), t) \\
& =\frac{e^{-r(T-t)}}{\sqrt{2 \pi}} \int_{X_{e}+\delta \leq S \leq(1+\alpha)\left(X_{e}+\delta\right)} V_{T 3}(\cdot) e^{-Z^{2} / 2} d Z \\
& V_{4}(S(t), t)=\frac{e^{-r(T-t)}}{\sqrt{2 \pi}} \int_{S \geq(1+\alpha)\left(X_{e}+\delta\right)} V_{T 4}(\cdot) e^{-Z^{2} / 2} d Z \\
& \text { and } V_{1}(S(t), t)=0 .
\end{aligned}
$$


Similar to Example 3 , let $U=$ $S(t) e^{\sigma \sqrt{T^{2 H}-t^{2 H}} Z+(T-t) r-\left(\sigma^{2} / 2\right)\left(T^{2 H}-t^{2 H}\right)}$. When $X_{e} \leq U \leq X_{e}+\delta$, we have

$$
\begin{aligned}
& \frac{\ln \left(X_{e} / S\right)-(T-t) r+\left(\sigma^{2} / 2\right)\left(T^{2 H}-t^{2 H}\right)}{\sigma \sqrt{T^{2 H}-t^{2 H}}} \leq Z \\
& \leq \frac{\ln \left(\left(X_{e}+\delta\right) / S\right)-(T-t) r+\left(\sigma^{2} / 2\right)\left(T^{2 H}-t^{2 H}\right)}{\sigma \sqrt{T^{2 H}-t^{2 H}}} .
\end{aligned}
$$

When $X_{e}+\delta \leq U \leq(1+\alpha)\left(X_{e}+\delta\right)$, we have

$$
\begin{aligned}
& \frac{\ln \left(\left(X_{e}+\delta\right) / S\right)-(T-t) r+\left(\sigma^{2} / 2\right)\left(T^{2 H}-t^{2 H}\right)}{\sigma \sqrt{T^{2 H}-t^{2 H}}} \leq Z \\
& \leq \frac{\ln \left((1+\alpha)\left(X_{e}+\delta\right) / S\right)-(T-t) r+\left(\sigma^{2} / 2\right)\left(T^{2 H}-t^{2 H}\right)}{\sigma \sqrt{T^{2 H}-t^{2 H}}} .
\end{aligned}
$$

When $U \geq(1+\alpha)\left(X_{e}+\delta\right)$, we have

Z

$$
\geq \frac{\ln \left((1+\alpha)\left(X_{e}+\delta\right) / S\right)-(T-t) r+\left(\sigma^{2} / 2\right)\left(T^{2 H}-t^{2 H}\right)}{\sigma \sqrt{T^{2 H}-t^{2 H}}} .
$$

To simplify the above expressions, let

$$
\begin{aligned}
& d_{1}=\frac{\ln \left(X_{e} / S\right)-(T-t) r+\left(\sigma^{2} / 2\right)\left(T^{2 H}-t^{2 H}\right)}{\sigma \sqrt{T^{2 H}-t^{2 H}}}, \\
& d_{2}=\frac{\ln \left(\left(X_{e}+\delta\right) / S\right)-(T-t) r+\left(\sigma^{2} / 2\right)\left(T^{2 H}-t^{2 H}\right)}{\sigma \sqrt{T^{2 H}-t^{2 H}}}, \\
& d_{3} \\
& =\frac{\ln \left((1+\alpha)\left(X_{e}+\delta\right) / S\right)-(T-t) r+\left(\sigma^{2} / 2\right)\left(T^{2 H}-t^{2 H}\right)}{\sigma \sqrt{T^{2 H}-t^{2 H}}} .
\end{aligned}
$$

Then,

$$
\begin{aligned}
& V_{2}(S(t), t)=\frac{e^{-r(T-t)}}{\sqrt{2 \pi}} \\
& \cdot \int_{d_{1}}^{d_{2}}\left(S(t) e^{\sigma \sqrt{T^{2 H}-t^{2 H}} Z+(T-t) r-\left(\sigma^{2} / 2\right)\left(T^{2 H}-t^{2 H}\right)}-X_{e}\right) \\
& \cdot e^{-Z^{2} / 2} d Z=\frac{S(t)}{\sqrt{2 \pi}} \int_{d_{1}}^{d_{2}} e^{-(1 / 2)\left(Z-\sigma \sqrt{\left.T^{2 H}-t^{2 H}\right)^{2}}\right.} d Z \\
& -\frac{X_{e} e^{-(T-t) r}}{\sqrt{2 \pi}} \int_{d_{1}}^{d_{2}} e^{-Z^{2} / 2} d Z=\frac{S(t)}{\sqrt{2 \pi}} \\
& \cdot \int_{d_{1}-\sigma \sqrt{T^{2 H}-t^{2 H}}}^{d_{2}-\sigma \sqrt{T^{2 H}-t^{2 H}}} e^{-(1 / 2)\left(Z-\sigma \sqrt{\left.T^{2 H}-t^{2 H}\right)^{2}}\right.} d(Z \\
& \left.-\sigma \sqrt{T^{2 H}-t^{2 H}}\right)-\frac{X_{e} e^{-(T-t) r}}{\sqrt{2 \pi}} \int_{d_{1}}^{d_{2}} e^{-Z^{2} / 2} d Z \\
& =S(t)\left(N\left(d_{2}-\sigma \sqrt{T^{2 H}-t^{2 H}}\right)-N\left(d_{1}\right.\right. \\
& \left.\left.-\sigma \sqrt{T^{2 H}-t^{2 H}}\right)\right)-X_{e} e^{-(T-t) r}\left(N\left(d_{2}\right)-N\left(d_{1}\right)\right) .
\end{aligned}
$$

The expression of $V_{T 3}(\cdot)$ must be simplified for the sake of feasibility. Let $\Sigma=\sigma \sqrt{T^{2 H}-t^{2 H}} Z+(T-t) r-\left(\sigma^{2} / 2\right)\left(T^{2 H}-\right.$ $\left.t^{2 H}\right)$; then

$$
\begin{aligned}
V_{\mathrm{T} 3}(\cdot) & =S(t)\left(1+\frac{\left(\beta-\beta_{0}\right) X_{e}}{\alpha\left(X_{e}+\delta\right)}-\frac{\beta_{0} X_{e}}{X_{e}+\delta}\right) e^{\Sigma}-(1 \\
+ & \left.\frac{\left(\beta-\beta_{0}\right) X_{e}}{\alpha\left(X_{e}+\delta\right)}-\frac{\beta_{0} X_{e}}{X_{e}+\delta}\right) X_{e} \\
& -\frac{\left(\beta-\beta_{0}\right) X_{e} S(t)}{\alpha\left(X_{e}+\delta\right)}\left(\ln \frac{S(t)}{X_{e}+\delta}+\Sigma\right) e^{\Sigma} \\
& -\frac{\left(\left(\beta-\beta_{0}\right)-\alpha \beta_{0}\right) X_{e} \delta}{\alpha\left(X_{e}+\delta\right)}=\{S(t)(1 \\
+ & \left.\frac{\left(\beta-(1+\alpha) \beta_{0}\right) X_{e}}{\alpha\left(X_{e}+\delta\right)}\right) \\
- & \frac{\left(\beta-\beta_{0}\right) X_{e} S(t)}{\alpha\left(X_{e}+\delta\right)}\left[\ln \frac{S(t)}{X_{e}+\delta}+(T-t) r\right. \\
- & \left.\left.\frac{\sigma^{2}}{2}\left(T^{2 H}-t^{2 H}\right)\right]\right\} e^{\Sigma}-\frac{\left(\beta-\beta_{0}\right) X_{e} S(t)}{\alpha\left(X_{e}+\delta\right)} \\
& \cdot \sigma \sqrt{T^{2 H}-t^{2 H}} e^{\Sigma} Z-\left(1+\frac{\left(\beta-(1+\alpha) \beta_{0}\right) X_{e}}{\alpha\left(X_{e}+\delta\right)}\right) \\
\cdot & X_{e}-\frac{\left(\beta-(1+\alpha) \beta_{0}\right) X_{e} \delta}{\alpha\left(X_{e}+\delta\right)} .
\end{aligned}
$$

If

$$
\begin{aligned}
M_{1} & =S(t)\left(1+\frac{\left(\beta-(1+\alpha) \beta_{0}\right) X_{e}}{\alpha\left(X_{e}+\delta\right)}\right) \\
& -\frac{\left(\beta-\beta_{0}\right) X_{e} S(t)}{\alpha\left(X_{e}+\delta\right)}\left[\ln \frac{S(t)}{X_{e}+\delta}+(T-t) r\right. \\
& \left.-\frac{\sigma^{2}}{2}\left(T^{2 H}-t^{2 H}\right)\right] \\
M_{2} & =\frac{\left(\beta-\beta_{0}\right) X_{e} S(t)}{\alpha\left(X_{e}+\delta\right)} \sigma \sqrt{T^{2 H}-t^{2 H}} \\
M_{3} & =\left(1+\frac{\left(\beta-(1+\alpha) \beta_{0}\right) X_{e}}{\alpha\left(X_{e}+\delta\right)}\right) X_{e} \\
& +\frac{\left(\beta-(1+\alpha) \beta_{0}\right) X_{e} \delta}{\alpha\left(X_{e}+\delta\right)},
\end{aligned}
$$

then $V_{T 3}(\cdot)$ can be further simplified into

$$
V_{T 3}(\cdot)=M_{1} e^{\Sigma}-M_{2} e^{\Sigma} Z-M_{3} .
$$


Therefore,

$$
\begin{aligned}
& V_{3}(S(t), t)=M_{1} e^{\Sigma}-M_{2} e^{\Sigma} Z-M_{3}=\frac{e^{-(T-t) r}}{\sqrt{2 \pi}} \\
& \cdot \int_{d_{2}}^{d_{3}}\left(M_{1} e^{\Sigma}-M_{2} e^{\Sigma} Z-M_{3}\right) e^{-Z^{2} / 2} d Z=\frac{M_{1}}{\sqrt{2 \pi}} \\
& \cdot \int_{d_{2}-\sigma \sqrt{T^{2 H}-t^{2 H}}}^{d_{3}-\sigma \sqrt{T^{2 H}-t^{2 H}}} e^{-\left(Z-\sigma \sqrt{T^{2 H}-t^{2 H}}\right)^{2} / 2} d(Z \\
& \left.-\sigma \sqrt{T^{2 H}-t^{2 H}}\right)-\frac{e^{-(T-t) r}}{\sqrt{2 \pi}} \int_{d_{2}}^{d_{3}}\left(M_{2} e^{\Sigma} Z+M_{3}\right) \\
& \cdot e^{-Z^{2} / 2} d Z=M_{1}\left[N\left(d_{3}-\sigma \sqrt{T^{2 H}-t^{2 H}}\right)\right. \\
& \left.-N\left(d_{2}-\sigma \sqrt{T^{2 H}-t^{2 H}}\right)\right]-M_{3} e^{-(T-t) r}\left[N\left(d_{3}\right)\right. \\
& \left.-N\left(d_{2}\right)\right]-\frac{M_{2}}{\sqrt{2 \pi}} \\
& \cdot \int_{d_{2}-\sigma \sqrt{T^{2 H}-t^{2 H}}}^{d_{3}-\sigma \sqrt{T^{2 H}-t^{2 H}}} e^{-\left(Z-\sigma \sqrt{T^{2 H}-t^{2 H}}\right)^{2} / 2} Z d(Z \\
& \left.-\sigma \sqrt{T^{2 H}-t^{2 H}}\right)=M_{1}\left[N\left(d_{3}-\sigma \sqrt{T^{2 H}-t^{2 H}}\right)\right. \\
& \left.-N\left(d_{2}-\sigma \sqrt{T^{2 H}-t^{2 H}}\right)\right]-M_{3} e^{-(T-t) r}\left[N\left(d_{3}\right)\right. \\
& \left.-N\left(d_{2}\right)\right]-\frac{M_{2}}{\sqrt{2 \pi}}\left(e^{-\left(d_{3}-\sigma \sqrt{T^{2 H}-t^{2 H}}\right)^{2} / 2}\right. \\
& \left.-e^{-\left(d_{2}-\sigma \sqrt{T^{2 H}-t^{2 H}}\right)^{2} / 2}\right)-\sigma \sqrt{T^{2 H}-t^{2 H}} M_{2}\left[N \left(d_{3}\right.\right. \\
& \left.\left.-\sigma \sqrt{T^{2 H}-t^{2 H}}\right)-N\left(d_{2}-\sigma \sqrt{T^{2 H}-t^{2 H}}\right)\right] .
\end{aligned}
$$

Similarly, let $\mathrm{M}_{4}=1-\beta_{0} X_{e} /\left(X_{e}+\delta\right)-\left(\left(\beta-\beta_{0}\right) X_{e} / \alpha\left(X_{e}+\right.\right.$ $\delta)) \ln (1+\alpha)$ Then $\mathrm{V}_{\mathrm{T} 4}(\cdot)$ can be simplified into $\mathrm{V}_{\mathrm{T} 4}(\cdot)=$ $M_{4} S e^{\Sigma}-(1-\beta) \mathrm{X}_{\mathrm{e}}$. Thus,

$$
\begin{aligned}
& V_{4}(S(t), t)=\frac{e^{-(T-t) r}}{\sqrt{2 \pi}}\left\{\int_{d_{3}}^{+\infty} M_{4} S(t) e^{\Sigma} e^{-Z^{2} / 2} d Z\right. \\
& \left.-\int_{d_{3}}^{+\infty}(1-\beta) X_{e} e^{-Z^{2} / 2} d Z\right\}=\frac{M_{4} S(t)}{\sqrt{2 \pi}} \\
& \cdot \int_{d_{3}-\sigma \sqrt{T^{2 H}-t^{2 H}}}^{+\infty} e^{-\left(Z-\sigma \sqrt{\left.T^{2 H}-t^{2 H}\right)^{2} / 2} d(Z\right.} \\
& \left.-\sigma \sqrt{T^{2 H}-t^{2 H}}\right)-\frac{(1-\beta) X_{e} e^{-(T-t) r}}{\sqrt{2 \pi}} \\
& \cdot \int_{d_{3}}^{+\infty} e^{-Z^{2} / 2} d Z=M_{4} S(t)\left(1-N\left(d_{3}\right.\right. \\
& \left.\left.-\sigma \sqrt{T^{2 H}-t^{2 H}}\right)\right)-(1-\beta) X_{e} e^{-(T-t) r}(1 \\
& \left.-N\left(d_{3}\right)\right) .
\end{aligned}
$$

Consequently, the final pricing formula for the proactive hedging option is

$$
\begin{aligned}
V_{F E c} & (S(t), t) \\
= & V_{1}(S(t), t)+V_{2}(S(t), t)+V_{3}(S(t), t) \\
& +V_{4}(S(t), t) \\
= & S(t)\left(N\left(d_{5}\right)-N\left(d_{4}\right)\right) \\
& -X_{e} e^{-(T-t) r}\left(N\left(d_{2}\right)-N\left(d_{1}\right)\right) \\
& +M_{1}\left[N\left(d_{6}\right)-N\left(d_{5}\right)\right] \\
& -M_{3} e^{-(T-t) r}\left[N\left(d_{3}\right)-N\left(d_{2}\right)\right] \\
& -\frac{M_{2}}{\sqrt{2 \pi}}\left(e^{-d_{6}{ }^{2} / 2}-e^{-d_{5}{ }^{2} / 2}\right) \\
& -\sigma \sqrt{T^{2 H}-t^{2 H}} M_{2}\left[N\left(d_{6}\right)-N\left(d_{5}\right)\right] \\
& +M_{4} S(t)\left(1-N\left(d_{6}\right)\right) \\
& -(1-\beta) X_{e} e^{-(T-t) r}\left(1-N\left(d_{3}\right)\right)
\end{aligned}
$$

where

$$
\begin{aligned}
& d_{1}=\frac{\ln \left(X_{e} / S(t)\right)-(T-t) r+\left(\sigma^{2} / 2\right)\left(T^{2 H}-t^{2 H}\right)}{\sigma \sqrt{T^{2 H}-t^{2 H}}}, \\
& d_{2}=\frac{\ln \left(\left(X_{e}+\delta\right) / S(t)\right)-(T-t) r+\left(\sigma^{2} / 2\right)\left(T^{2 H}-t^{2 H}\right)}{\sigma \sqrt{T^{2 H}-t^{2 H}}}, \\
& d_{3} \\
& =\frac{\ln \left((1+\alpha)\left(X_{e}+\delta\right) / S(t)\right)-(T-t) r+\left(\sigma^{2} / 2\right)\left(T^{2 H}-t^{2 H}\right)}{\sigma \sqrt{T^{2 H}-t^{2 H}}}, \\
& d_{4}=d_{1}-\sigma \sqrt{T^{2 H}-t^{2 H}}, \\
& d_{5}=d_{2}-\sigma \sqrt{T^{2 H}-t^{2 H}}, \\
& d_{6}=d_{3}-\sigma \sqrt{T^{2 H}-t^{2 H}}, \\
& M_{1} \\
& =S(t)\left(1+\frac{\left(\beta-(1+\alpha) \beta_{0}\right) X_{e}}{\alpha\left(X_{e}+\delta\right)}\right) \\
& -\frac{\left(\beta-\beta_{0}\right) X_{e} S(t)}{\alpha\left(X_{e}+\delta\right)}\left[\ln \frac{S(t)}{X_{e}+\delta}+(T-t) r-\frac{\sigma^{2}}{2}\left(T^{2 H}-t^{2 H}\right)\right], \\
& M_{2}=\frac{\left(\beta-\beta_{0}\right) X_{e} S(t)}{\alpha\left(X_{e}+\delta\right)} \sigma \sqrt{T^{2 H}-t^{2 H}}, \\
& M_{3}=\left(1+\frac{\left(\beta-(1+\alpha) \beta_{0}\right) X_{e}}{\alpha\left(X_{e}+\delta\right)}\right) X_{e}+\frac{\left(\beta-(1+\alpha) \beta_{0}\right) X_{e} \delta}{\alpha\left(X_{e}+\delta\right)} \text {, } \\
& M_{4}=1-\frac{\beta_{0} X_{e}}{X_{e}+\delta}-\frac{\left(\beta-\beta_{0}\right) X_{e}}{\alpha\left(X_{e}+\delta\right)} \ln (1+\alpha) .
\end{aligned}
$$

At this point, the pricing formula for a proactive hedging option with linear position strategy is obtained.

3.5. Pricing Formula Discussion. This subsection discusses some special forms of the pricing formula presented in 
Section 3.4. The pricing formula in (39) has three sets of parameters. The first set is the Hurst index $H$, which represents the dependence in the process of the underlying asset price. The second set includes parameters $\left(\alpha, \beta, \beta_{0}, \delta\right)$, which describe the linear position strategy. The third set includes parameters $\left(r, T, \sigma, X_{e}\right)$, which are the basic parameters for the pricing of a classical European option. Below, we discuss several special cases based on these three sets of parameters.

(a) Consider a Hurst parameter $H=1 / 2$. In this case, price of underlying asset follows GBM and the pricing formula in (39) can accordingly be reduced into the following:

$$
\begin{aligned}
V_{E c}(S(t), t)= & V_{1}(S(t), t)+V_{2}(S(t), t) \\
& +V_{3}(S(t), t)+V_{4}(S(t), t) \\
= & S(t)\left(N\left(d_{5}\right)-N\left(d_{4}\right)\right) \\
& -X_{e} e^{-(T-t) r}\left(N\left(d_{2}\right)-N\left(d_{1}\right)\right) \\
& +M_{1}\left[N\left(d_{6}\right)-N\left(d_{5}\right)\right] \\
& -M_{3} e^{-(T-t) r}\left[N\left(d_{3}\right)-N\left(d_{2}\right)\right] \\
& -\frac{M_{2}}{\sqrt{2 \pi}}\left(e^{-d_{6}{ }^{2} / 2}-e^{-d_{5}{ }^{2} / 2}\right) \\
& -\sigma \sqrt{T-t} M_{2}\left[N\left(d_{6}\right)-N\left(d_{5}\right)\right] \\
& +M_{4} S(t)\left(1-N\left(d_{6}\right)\right) \\
& -(1-\beta) X_{e} e^{-(T-t) r}\left(1-N\left(d_{3}\right)\right),
\end{aligned}
$$

where

$$
\begin{aligned}
d_{1} & =\frac{\ln \left(X_{e} / S\right)-(T-t) r+\left(\sigma^{2} / 2\right)(T-t)}{\sigma \sqrt{T-t}}, \\
d_{2} & =\frac{\ln \left(\left(X_{e}+\delta\right) / S\right)-(T-t) r+\left(\sigma^{2} / 2\right)(T-t)}{\sigma \sqrt{T-t}}, \\
d_{3} & =\frac{\ln \left((1+\alpha)\left(X_{e}+\delta\right) / S\right)-(T-t) r+\left(\sigma^{2} / 2\right)(T-t)}{\sigma \sqrt{T-t}}, \\
d_{4} & =d_{1}-\sigma \sqrt{T-t}, \\
d_{5} & =d_{2}-\sigma \sqrt{T-t}, \\
d_{6} & =d_{3}-\sigma \sqrt{T-t}, \\
M_{1} & =S(t)\left(1+\frac{\left(\beta-(1+\alpha) \beta_{0}\right) X_{e}}{\alpha\left(X_{e}+\delta\right)}\right) \\
& -\frac{\left(\beta-\beta_{0}\right) X_{e} S(t)}{\alpha\left(X_{e}+\delta\right)}\left[\ln \frac{S(t)}{X_{e}+\delta}+(T-t) r\right. \\
& \left.-\frac{\sigma^{2}}{2}(T-t)\right], \\
M_{2} & =\frac{\left(\beta-\beta_{0}\right) X_{e} S(t)}{\alpha\left(X_{e}+\delta\right)} \sigma \sqrt{T-t},
\end{aligned}
$$

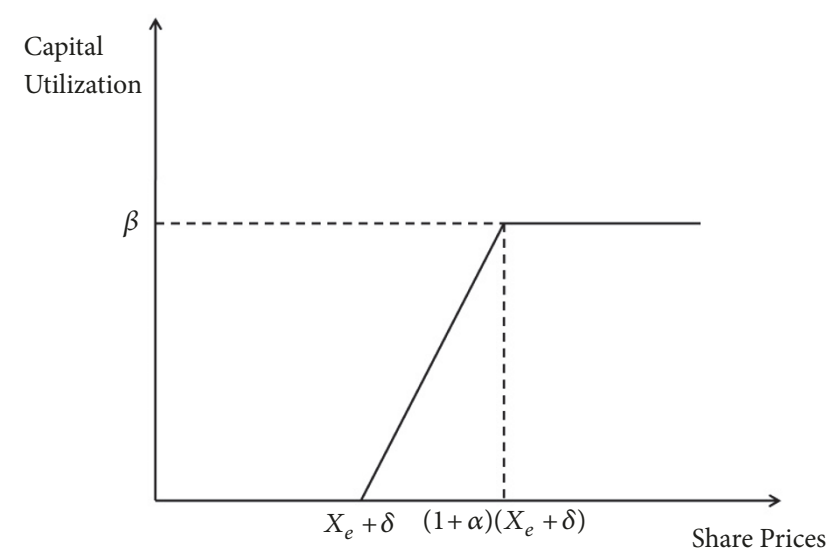

FIGURE 2: Capital utilization function with linear position strategy when $\beta_{0}=0$.

$$
\begin{aligned}
M_{3} & =\left(1+\frac{\left(\beta-(1+\alpha) \beta_{0}\right) X_{e}}{\alpha\left(X_{e}+\delta\right)}\right) X_{e} \\
& +\frac{\left(\beta-(1+\alpha) \beta_{0}\right) X_{e} \delta}{\alpha\left(X_{e}+\delta\right)}, \\
M_{4} & =1-\frac{\beta_{0} X_{e}}{X_{e}+\delta}-\frac{\left(\beta-\beta_{0}\right) X_{e}}{\alpha\left(X_{e}+\delta\right)} \ln (1+\alpha) .
\end{aligned}
$$

In this study, we took a different approach from the B$S$ method to obtain the pricing formula. Although both methods are based on the hypothesis of a risk-neutral world, we focused on whether the results of the two approaches are consistent. We further simplified (41) by letting $\beta=\beta_{0}=0$, which reflects an option holder who does not participate in any self-defense, so that the problem setting is identical to that of the classical European option. We then compared the results obtained by two approaches. The simplified formula version of (41) is

$$
V_{c}(S(t), t)=S(t)\left(N\left(d_{1}\right)\right)-X_{e} e^{-(T-t) r}\left(N\left(d_{2}\right)\right),
$$

where

$$
\begin{aligned}
& d_{1}=\frac{\ln \left(S(t) / X_{e}\right)+(T-t) r+\left(\sigma^{2} / 2\right)(T-t)}{\sigma \sqrt{T-t}}, \\
& d_{2}=\frac{\ln \left(S(t) / X_{e}\right)+(T-t) r-\left(\sigma^{2} / 2\right)(T-t)}{\sigma \sqrt{T-t}} .
\end{aligned}
$$

Clearly, this result is in accordance with the classical B-S formula.

We investigated two boundary position strategies as special cases. The first case is when $\beta_{0}=0$, where the linear position strategy is shown in Figure 2. 
When the linear position strategy in Figure 2 applies, the pricing formula is

$$
\begin{aligned}
V_{F \beta_{0} c}( & t, S(t)) \\
= & V_{1}(S(t), t)+V_{2}(S(t), t)+V_{3}(S(t), t) \\
& +V_{4}(S(t), t) \\
= & S(t)\left(N\left(d_{5}\right)-N\left(d_{4}\right)\right) \\
& -X_{e} e^{-(T-t) r}\left(N\left(d_{2}\right)-N\left(d_{1}\right)\right) \\
& +M_{1}\left[N\left(d_{6}\right)-N\left(d_{5}\right)\right] \\
& -M_{3} e^{-(T-t) r}\left[N\left(d_{3}\right)-N\left(d_{2}\right)\right] \\
& -\frac{M_{2}}{\sqrt{2 \pi}}\left(e^{-d_{6}^{2} / 2}-e^{-d_{5}^{2} / 2}\right) \\
& -\sigma \sqrt{T^{2 H}-t^{2 H}} M_{2}\left[N\left(d_{6}\right)-N\left(d_{5}\right)\right] \\
& +M_{4} S(t)\left(1-N\left(d_{6}\right)\right) \\
& -(1-\beta) X_{e} e^{-(T-t) r}\left(1-N\left(d_{3}\right)\right)
\end{aligned}
$$

where

$$
\begin{aligned}
& d_{1}=\frac{\ln \left(X_{e} / S(t)\right)-(T-t) r+\left(\sigma^{2} / 2\right)\left(T^{2 H}-t^{2 H}\right)}{\sigma \sqrt{T^{2 H}-t^{2 H}}}, \\
& d_{2}=\frac{\ln \left(\left(X_{e}+\delta\right) / S(t)\right)-(T-t) r+\left(\sigma^{2} / 2\right)\left(T^{2 H}-t^{2 H}\right)}{\sigma \sqrt{T^{2 H}-t^{2 H}}}, \\
& d_{3} \\
& =\frac{\ln \left((1+\alpha)\left(X_{e}+\delta\right) / S(t)\right)-(T-t) r+\left(\sigma^{2} / 2\right)\left(T^{2 H}-t^{2 H}\right)}{\sigma \sqrt{T^{2 H}-t^{2 H}}}, \\
& d_{4}=d_{1}-\sigma \sqrt{T^{2 H}-t^{2 H}}, \\
& d_{5}=d_{2}-\sigma \sqrt{T^{2 H}-t^{2 H}}, \\
& d_{6}=d_{3}-\sigma \sqrt{T^{2 H}-t^{2 H}}, \\
& M_{1} \\
& =S(t)\left(1+\frac{\beta X_{e}}{\alpha\left(X_{e}+\delta\right)}\right) \\
& M_{4}=1-\frac{\beta X_{e}}{\alpha\left(X_{e}+\delta\right)} \ln (1+\alpha) . \\
& M_{3}=\left(1+\frac{\beta X_{e} S(t)}{\alpha\left(X_{e}+\delta\right)}\left[\ln \frac{S(t)}{X_{e}+\delta}+(T-t) r-\frac{\sigma^{2}}{2}\left(T^{2 H}-t^{2 H}\right)\right]\right. \\
& M_{2}=\frac{\beta X_{e} S(t)}{\alpha\left(X_{e}+\delta\right)} \sigma \sqrt{T^{2 H}-t^{2 H}}, \\
& \alpha\left(X_{e}+\delta\right)
\end{aligned}
$$

The second special case is when $\beta=\beta_{0}=1$, where the option holder purchases all the possible stock at the price $X_{e}+\delta$. The capital utilization under this linear position strategy is shown in Figure 3.

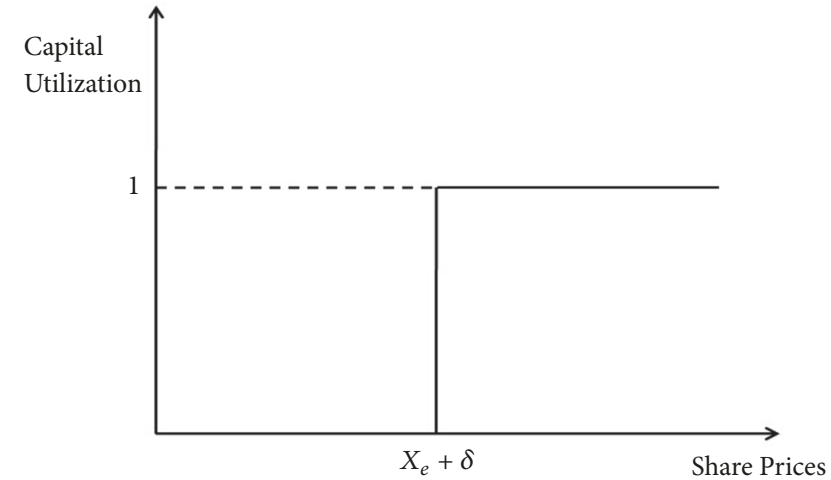

Figure 3: Capital utilization function with linear position strategy when $\beta=\beta_{0}=1$.

In this case, the corresponding pricing formula is

$$
\begin{aligned}
V_{F \beta c}(S(t), t)= & S(t)\left(N\left(d_{4}\right)-N\left(d_{3}\right)\right) \\
& -X_{e} e^{-(T-t) r}\left(N\left(d_{2}\right)-N\left(d_{1}\right)\right) \\
& +\frac{S(t) \delta}{X_{e}+\delta}\left[1-N\left(d_{4}\right)\right]
\end{aligned}
$$

where

$$
\begin{aligned}
& d_{1}=\frac{\ln \left(X_{e} / S(t)\right)-(T-t) r+\left(\sigma^{2} / 2\right)\left(T^{2 H}-t^{2 H}\right)}{\sigma \sqrt{T^{2 H}-t^{2 H}}}, \\
& d_{2} \\
& =\frac{\ln \left(\left(X_{e}+\delta\right) / S(t)\right)-(T-t) r+\left(\sigma^{2} / 2\right)\left(T^{2 H}-t^{2 H}\right)}{\sigma \sqrt{T^{2 H}-t^{2 H}}}, \\
& d_{3}=d_{1}-\sigma \sqrt{T^{2 H}-t^{2 H}}, \\
& d_{4}=d_{2}-\sigma \sqrt{T^{2 H}-t^{2 H}} .
\end{aligned}
$$

If we add an additional condition $\delta=0$ to the condition of $\beta=\beta_{0}=1$, that is, the option holder must hold all the available stocks at the exercising price, then the value of the exotic option drops to zero.

\section{Theoretical Prices of Proactive Hedging Option and Classical European Option}

We next calculated the theoretical price of the exotic option which allows a proactive hedging strategy under formula (39) and that of the classical European option by formula (41), respectively. Our calculation parameter settings are shown in Table 1. For simplicity, we assume $t=0$ across all calculations in this section.

We calculated the price of the proactive hedging option with linear position strategy as well as that of the classical European option for every possible parameter combination generated by values in Table 1, and then we determined the ratio of these two prices for each particular parameter setting as listed in Table 2. The first four columns denote 
TABLE 1: Parameter settings

\begin{tabular}{lccc}
\hline Symbol & Values & Symbol & Values \\
\hline$H$ & $0.5,0.7,0.9$ & $T$ & 0.5 (half of one year) \\
$\alpha$ & $50 \%, 70 \%, 100 \%$ & $S_{0}$ & $\$ 20$ per share \\
$\beta$ & $80 \%, 100 \%$ & $X_{e}$ & $\$ 20$ per share \\
$\beta_{0}$ & $0,50 \%$ & $\sigma$ & $30 \%$ \\
$\delta$ & $\$ 0, \$ 4, \$ 10$ per share & $r$ & $6 \%$ \\
\hline
\end{tabular}

TABle 2: Price ratios of exotic option allowing proactive hedging relative to classical European option under constant parameters $\left(\alpha, \beta, \beta_{0}, \delta\right)$.

\begin{tabular}{|c|c|c|c|c|c|c|}
\hline \multirow[b]{2}{*}{$\alpha$} & \multirow[b]{2}{*}{$\beta$} & \multirow[b]{2}{*}{$\beta_{0}$} & \multirow[b]{2}{*}{$\delta$} & \multicolumn{3}{|c|}{ price ratios } \\
\hline & & & & $H=0.5$ & $H=0.7$ & $H=0.9$ \\
\hline $50 \%$ & $80 \%$ & 0 & 0 & 0.77 & 0.80 & 0.82 \\
\hline $50 \%$ & $80 \%$ & 0 & 4 & 0.95 & 0.97 & 0.98 \\
\hline $50 \%$ & $80 \%$ & 0 & 10 & 1.00 & 1.00 & 1.00 \\
\hline $50 \%$ & $80 \%$ & $50 \%$ & 0 & 0.41 & 0.42 & 0.43 \\
\hline $50 \%$ & $80 \%$ & $50 \%$ & 4 & 0.85 & 0.88 & 0.91 \\
\hline $50 \%$ & $80 \%$ & $50 \%$ & 10 & 0.99 & 0.99 & 1.00 \\
\hline $50 \%$ & $100 \%$ & 0 & 0 & 0.71 & 0.74 & 0.78 \\
\hline $50 \%$ & $100 \%$ & 0 & 4 & 0.94 & 0.96 & 0.97 \\
\hline $50 \%$ & $100 \%$ & 0 & 10 & 1.00 & 1.00 & 1.00 \\
\hline $50 \%$ & $100 \%$ & $50 \%$ & 0 & 0.35 & 0.37 & 0.39 \\
\hline $50 \%$ & $100 \%$ & $50 \%$ & 4 & 0.84 & 0.87 & 0.90 \\
\hline $50 \%$ & $100 \%$ & $50 \%$ & 10 & 0.98 & 0.99 & 1.00 \\
\hline $70 \%$ & $80 \%$ & 0 & 0 & 0.83 & 0.85 & 0.87 \\
\hline $70 \%$ & $80 \%$ & 0 & 4 & 0.97 & 0.98 & 0.99 \\
\hline $70 \%$ & $80 \%$ & 0 & 10 & 1.00 & 1.00 & 1.00 \\
\hline $70 \%$ & $80 \%$ & $50 \%$ & 0 & 0.44 & 0.44 & 0.45 \\
\hline $70 \%$ & $80 \%$ & $50 \%$ & 4 & 0.85 & 0.88 & 0.91 \\
\hline $70 \%$ & $80 \%$ & $50 \%$ & 10 & 0.99 & 0.99 & 1.00 \\
\hline $70 \%$ & $100 \%$ & 0 & 0 & 0.79 & 0.82 & 0.84 \\
\hline $70 \%$ & $100 \%$ & 0 & 4 & 0.96 & 0.97 & 0.98 \\
\hline $70 \%$ & $100 \%$ & 0 & 10 & 1.00 & 1.00 & 1.00 \\
\hline $70 \%$ & $100 \%$ & $50 \%$ & 0 & 0.39 & 0.41 & 0.42 \\
\hline $70 \%$ & $100 \%$ & $50 \%$ & 4 & 0.85 & 0.88 & 0.91 \\
\hline $70 \%$ & $100 \%$ & $50 \%$ & 10 & 0.99 & 0.99 & 1.00 \\
\hline $100 \%$ & $80 \%$ & 0 & 0 & 0.88 & 0.90 & 0.91 \\
\hline $100 \%$ & $80 \%$ & 0 & 4 & 0.98 & 0.98 & 0.99 \\
\hline $100 \%$ & $80 \%$ & 0 & 10 & 1.00 & 1.00 & 1.00 \\
\hline $100 \%$ & $80 \%$ & $50 \%$ & 0 & 0.46 & 0.46 & 0.47 \\
\hline $100 \%$ & $80 \%$ & $50 \%$ & 4 & 0.86 & 0.89 & 0.91 \\
\hline $100 \%$ & $80 \%$ & $50 \%$ & 10 & 0.99 & 0.99 & 1.00 \\
\hline $100 \%$ & $100 \%$ & 0 & 0 & 0.85 & 0.87 & 0.89 \\
\hline $100 \%$ & $100 \%$ & 0 & 4 & 0.97 & 0.98 & 0.99 \\
\hline $100 \%$ & $100 \%$ & 0 & 10 & 1.00 & 1.00 & 1.00 \\
\hline $100 \%$ & $100 \%$ & $50 \%$ & 0 & 0.43 & 0.44 & 0.44 \\
\hline $100 \%$ & $100 \%$ & $50 \%$ & 4 & 0.85 & 0.88 & 0.91 \\
\hline $100 \%$ & $100 \%$ & $50 \%$ & 10 & 0.99 & 0.99 & 1.00 \\
\hline
\end{tabular}

the values of the parameters describing the linear position strategy. The last three columns are the price ratios for $H=$
$0.5,0.7,0.9$, respectively. For example, the theoretical price of the exotic option allowing proactive hedging with $H=$ $0.9, \alpha=0.5, \beta=80 \%$, and $\delta=\beta_{0}=0$ is 1.30 and that of the classical European option with the same parameter setting is 1.58 : the price ratio is $1.30 / 1.58=0.82$. The price ratio represents the extent to which the proactive hedging option with linear position strategy reduces the option price relative to the classical European option under the same parameters.

The price ratios in Table 2 represent three important observations.

(1) The theoretical price of the proactive hedging option does not exceed that of the classical option at any point, regardless of whether stock price changes are driven by GBM $(H=0.5)$ or GFBM $(\mathrm{H}=0.7$ or 0.9 in this illustration). In other words, the proactive hedging option always has a price advantage which is equal to 1 minus the price ratio, although sometimes the advantage is almost 0 (price ratio is 1) relative to the classical European option across all parameter settings. The maximum price advantage reaches up to $65 \%$ (price ratio is 0.35 ) based on the parameter settings here.

(2) All the four parameters $\left(\alpha, \beta, \beta_{0}, \delta\right)$ describing the position strategy have significant effects on the price advantage, especially $\beta_{0}$ and $\delta$. Our calculation results suggest that if the option holder spends half of the initial capital to initiate the position at the exercising price, then this exotic option is at least $50 \%$ cheaper than that of the classical option. However, if the option holder only begins to purchase stock when the price exceeds $20 \%$ of the exercising price, the price advantage of the exotic option drops almost to zero. The price advantage appears to be nearly solely dependent on how much capital is used to initiate the position at the exercising price.

(3) The price ratios are rather robust given the volatility of the stock price $\sigma$. When $H$ increases from 0.5 to 0.9 within each row, the price ratios are bounded within 0.06 of each other.

\section{Conclusions}

In this paper, we discussed the value and pricing of an exotic option which allows call option holders to conduct proactive hedging with a linear position strategy in the risk-neutral world. We also compared the price of such options to that of the classical European option under the same parameter settings. 
We found that it is indeed possible to apply a risk-neutral evaluation principle directly to the pricing of this exotic option. When the exotic option reduces to a classical European option, the pricing formula obtained by this approach is identical to that obtained by B-S model. We then compared the theoretical prices of such proactive hedging options with those of classical options under the same parameter settings. The proactive hedging option may have a considerable price advantage, up to $65 \%$, over the classical European options. This suggests that such a proactive hedging option may be of interest to the option holders in covering their risk of exposure at the sacrifice of leverage. The possible price advantage makes these options attractive in regard to future research and even option product designs.

We used several assumptions throughout the derivation and calculations presented in this paper. Most, like the risk-neutral assumption, are present in previous theoretical studies on option pricing as well. One unique assumption we made is that the linear position strategy has a continuous function, which allowed us to simplify the derivation, but this strategy may not be feasible in practice. In the future, we plan to secure a fully feasible linear position strategy as well as other nonlinear positions.

\section{Data Availability}

The data used to support the findings of this study are available from the corresponding author upon request.

\section{Conflicts of Interest}

The authors declare that they have no conflicts of interest.

\section{Acknowledgments}

This research is supported by the National Science Foundation of China (No. 71503060, No. 71532004, and No. 71301034) and Ministry of Education in China Project of Humanities and Social Sciences (No. 14YJC790065).

\section{References}

[1] D. Hackmann, "Analytic techniques for option pricing under a hyperexponential Levy model," Journal of Computational and Applied Mathematics, vol. 342, pp. 225-248, 2018.

[2] D. Sesana, D. Marazzina, and G. Fusai, "Pricing exotic derivatives exploiting structure," European Journal of Operational Research, vol. 236, no. 1, pp. 369-381, 2014.

[3] G. Bormetti, G. Callegaro, G. Livieri, and A. Pallavicini, "A backward Monte Carlo approach to exotic option pricing," European Journal of Applied Mathematics, vol. 29, no. 1, pp. 146187, 2018.

[4] P. Hieber, "Pricing exotic options in a regime switching economy: a Fourier transform method," Review of Derivatives Research, vol. 21, no. 2, pp. 231-252, 2018.

[5] L. Yan, "Pricing formula for exotic options with assets exposed to counterparty risk," Discrete Dynamics in Nature and Society, vol. 2017, Article ID 5239808, pp. 1-8, 2017.
[6] T. He, "EXPlicit Pricing Formulas for European Option with Asset EXPosed to Double DEFaults Risk," Discrete Dynamics in Nature and Society, Art. ID 8362912, 8 pages, 2018.

[7] X. Wang and L. Wang, "Study on black-scholes stock option pricing model based on dynamic investment strategy," International Journal of Innovative Computing, Information and Control, vol. 3, no. 6 B, pp. 1755-1780, 2007.

[8] X. F. Wang and L. Wang, "Study on Black-Scholes option pricing model based on general linear investment strategy(Part I:put option)," International Journal of Innovative Computing, Information and Control, vol. 5, no. 6, pp. 1765-1783, 2009.

[9] X. Wang and L. Wang, "Study on black-scholes option pricing model based on general linear investment strategy (part II: Call option)," International Journal of Innovative Computing, Information and Control, vol. 5, no. 8, pp. 2169-2188, 2009.

[10] F. Black and M. Scholes, "The pricing of options corporate liabilities," Journal of Political Economy, vol. 81, pp. 637-659, 1973.

[11] E. Vasile and D. Armeanu, "Empirical study on the performances of black-scholes model for evaluating european options," Romanian Journal of Economic Forecasting, vol. 10, no. 1, pp. 48-62, 2009.

[12] U. Cetin, R. Jarrow, P. Protter, and M. Warachka, "Pricing options in an extended Black Scholes economy with illiquidity: Theory and empirical evidence," Review of Financial Studies, vol. 19, no. 2, pp. 493-529, 2006.

[13] D. O. Cajueiro and B. M. Tabak, "The Hurst exponent over time: testing the assertion that emerging markets are becoming more efficient," Physica A: Statistical Mechanics and its Applications, vol. 336, no. 3-4, pp. 521-537, 2004.

[14] R. Weron, "Estimating long-range dependence: finite sample properties and confidence intervals," Physica A: Statistical Mechanics and its Applications, vol. 312, no. 1-2, pp. 285-299, 2002.

[15] D. O. Cajueiro and B. M. Tabak, "Testing for time-varying longrange dependence in volatility for emerging markets," Physica A: Statistical Mechanics and its Applications, vol. 346, no. 3-4, pp. 577-588, 2005.

[16] S. M. D. Queiros, "On non-Gaussianity and dependence in financial time series: a nonextensive approach," Quantitative Finance, vol. 5, no. 5, pp. 475-487, 2005.

[17] G. Dhesi and M. Ausloos, "Modelling and measuring the irrational behaviour of agents in financial markets: Discovering the psychological soliton," Chaos, Solitons \& Fractals, vol. 88, pp. 119-125, 2015.

[18] Q. Li, Y. L. Zhou, X. Q. Zhao, and X. Y. Ge, "Fractional order stochastic differential equation with application in European option pricing," Discrete Dynamics in Nature and Society, vol. 2014, Article ID 621895, 12 pages, 2014.

[19] C. Wang, S. W. Zhou, and J. Y. Yang, “The pricing of vulnerable options in a fractional brownian motion environment," Discrete Dynamics in Nature and Society, vol. 2015, Article ID 579213, 10 pages, 2015.

[20] J. C. Reboredo, M. A. Rivera-Castro, J. G. V. Miranda, and R. García-Rubio, "How fast do stock prices adjust to market efficiency? Evidence from a detrended fluctuation analysis," Physica A: Statistical Mechanics and its Applications, vol. 392, no. 7, pp. 1631-1637, 2013.

[21] M. Fernandez-Martinez and M. A. Sanchez-Granero, "Trinidad Segovia, Measuring the self-similarity exponent in Levy stable processes of financial time series," Physica A: Statistical Mechanics and Its Applications, vol. 159, no. 7, pp. 1825-1837, 2012. 
[22] F. Shokrollahi, "The evaluation of geometric Asian power options under time changed mixed fractional Brownian motion," Journal of Computational and Applied Mathematics, vol. 344, pp. 716-724, 2018.

[23] L. Wang, R. Zhang, L. Yang, Y. Su, and F. Ma, "Pricing geometric Asian rainbow options under fractional Brownian motion," Physica A: Statistical Mechanics and its Applications, vol. 494, pp. 8-16, 2018.

[24] M. Ye, R. Wang, G. Tuo, and T. Wang, "Crop price insurance in China: Pricing and hedging using futures market," China Agricultural Economic Review, vol. 9, no. 4, pp. 567-587, 2017.

[25] M. Misiran, Z. Lu, K. L. Teo, and G. Aw, "Estimating dynamic geometric fractional Brownian motion and its application to long-memory option pricing," Dynamic Systems and Applications, vol. 21, no. 1, pp. 49-66, 2012.

[26] J. C. Cox and S. A. Ross, "The valuation of options for alternative stochastic processes," Journal of Financial Economics, vol. 3, no. 1-2, pp. 145-166, 1976.

[27] Y. Hu and B. Øksendal, "Fractional white noise calculus and applications to finance," Infinite Dimensional Analysis, Quantum Probability and Related Topics, vol. 6, no. 1, pp. 1-32, 2003.

[28] C. Necula, "Option pricing in a fractional Brownian motion environment," Advances in Economic and Financial Research, vol. 2, no. 3, pp. 259-273, 2004. 


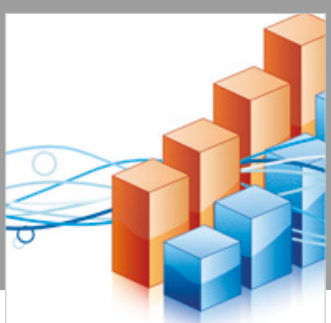

Advances in

Operations Research

\section{-n-m}
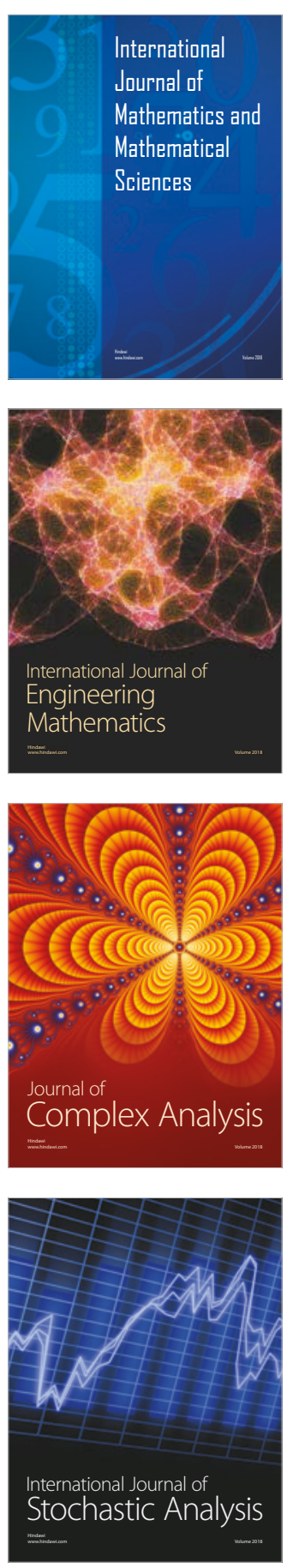
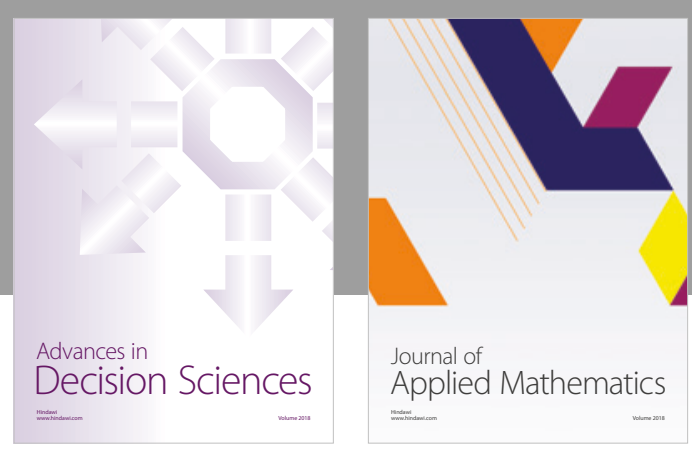

Journal of

Applied Mathematics
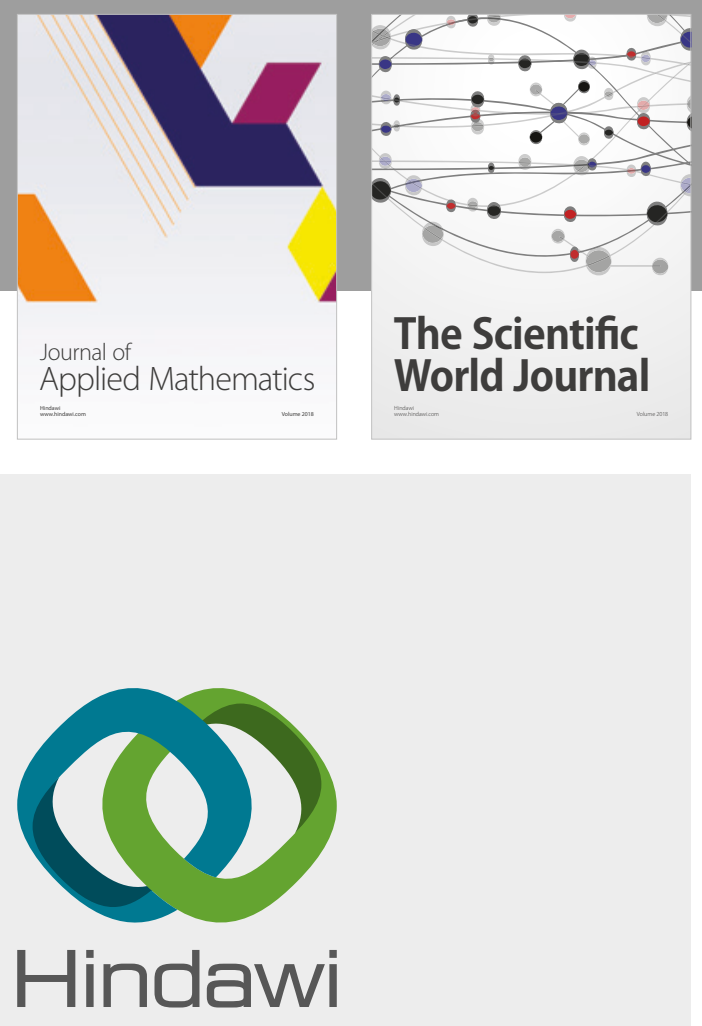

Submit your manuscripts at

www.hindawi.com

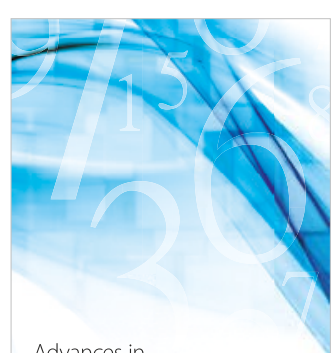

Advances in
Numerical Analysis
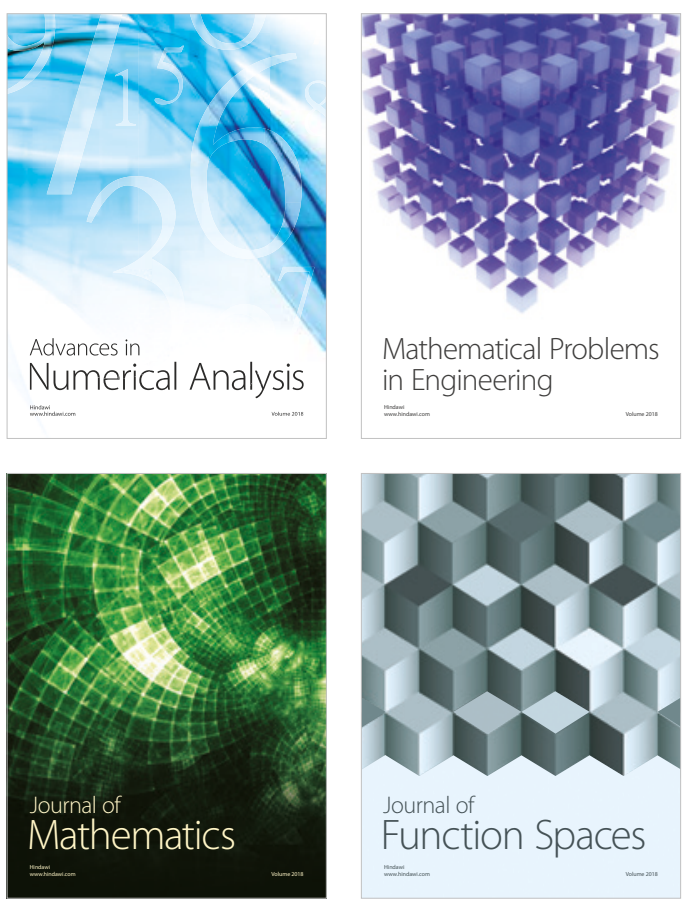

Mathematical Problems in Engineering

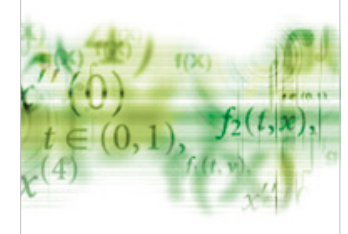

International Journal of

Differential Equations

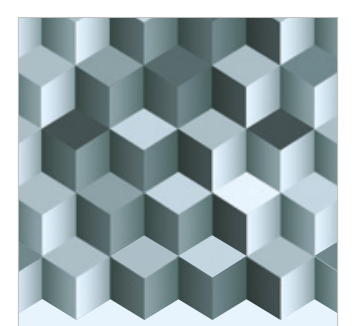

Journal of

Function Spaces

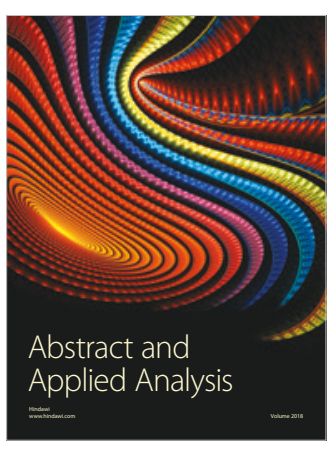

The Scientific

World Journal

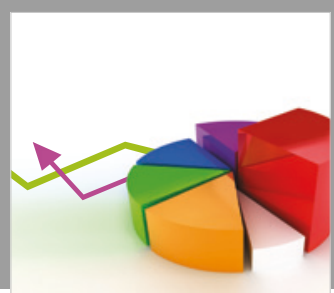

Journal of

Probability and Statistics
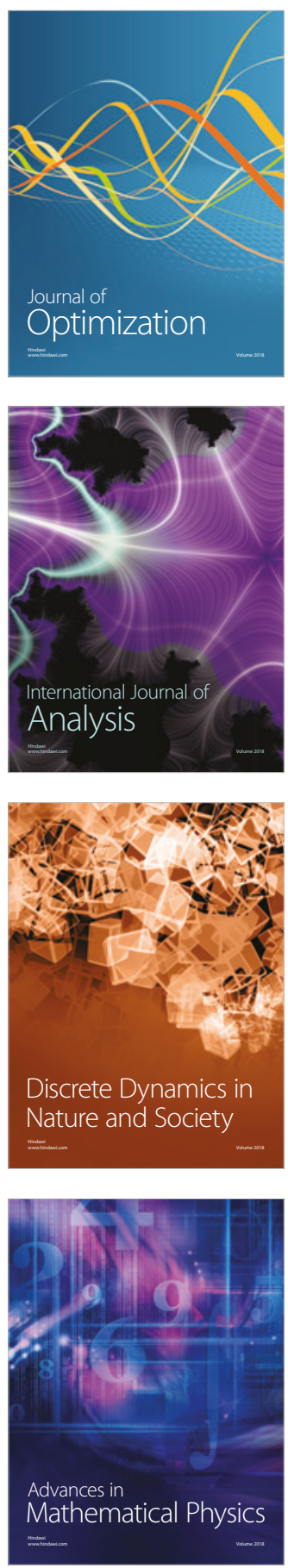